\title{
Hubungan Angka Kerapatan Panen dan Sistem Rotasi Panen Dengan Produktivitas Kelapa Sawit (Elaeis guineensis Jacq.) di Sumatera Utara
}

\section{The Relationship of Harvesting Density Number and Harvesting Rotation System with the Productivity of Oil Palm (Elaeis guineensis Jacq.) in North Sumatera}

\author{
Muhammad Irfan Miraza, Memen Surahman* \\ ${ }^{1}$ Departemen Agronomi dan Hortikultura, Fakultas Pertanian, Institut Pertanian Bogor \\ (Bogor Agricultural University), J1. Meranti, Kampus IPB Darmaga, Bogor 16680, Indonesia \\ Telp.\&Faks.62-251-8629353 e-mail agronipb@indo.net.id \\ *Penulis untuk korespondensi: memensurahman@yahoo.com
}

Disetujui 7 Januari 2015 / Published online 15 Januari 2015

\begin{abstract}
Activity took place from February to June 2014 at Tanjung Jati Plantation, PTPN II in North Sumatra. Observations were tested using quantitativemethod which consists of the sum, average, and percentage, while the statistical test was using t-student. Harvesting rotation, number of harvesting density, management of harvesting workers and crop productivity were important aspects of harvesting activities. Based on analysis conducted, the value of estimated AKP with realization was not significantly different. Harvesting workers became very crucial for the production of palm oil. The harvesting workers level of discipline which was still relatively low, as seen in the quality of "hanca" became one of the issues that must be considered to further improve the quality of the production of the company. Productivity of oil palm at Tanjung Jati Plantation was not yet in accordance with the Marihat standards.
\end{abstract}

Keywords: harvesting rotation, number of harvesting density, oil palm

\section{ABSTRAK}

Kegiatan berlangsung dari bulan Februari hingga Juni 2014 di kebun Tanjung Jati PTPN II, Sumatera Utara. Pengamatan diuji menggunakan metode kuantitatif yang terdiri dari penjumlahan, ratarata, dan persentase. Sedangkan uji statistik menggunakan t-student. Rotasi panen, angka kerapatan panen, manajemen tenaga panen dan produktivitas panen merupakan aspek penting dalam kegiatan panen. Berdasarkan hasil analisis yang dilakukan, nilai AKP estimasi dengan realisasi tidak berbeda nyata. Tenaga panen menjadi sangat menentukan bagi produksi kelapa sawit. Tingkat kedisiplinan tenaga panen yang masih tergolong rendah sebagaimana terlihat pada mutu hanca menjadi salah satu masalah yang harus diperhatikan untuk lebih meningkatkan kualitas produksi perusahaan. Produktivitas kelapa sawit di kebun belum sesuai dengan standar Marihat.

Kata kunci : angka kerapatan panen, kelapa sawit, sistem rotasi panen 


\section{PENDAHULUAN}

Kelapa sawit merupakan salah satu komoditas perkebunan yang menghasilkan minyak dan sebagai komoditas ekspor non migas yang dapat membantu perekonomian Indonesia. Tanaman kelapa sawit terdiri atas tiga produk komersial yang dihasilkan yaitu minyak sawit (CPO: crude palm oil), inti sawit (PKO: palm kernel oil), dan ampas inti sawit (Naibaho. 1990).

Indonesia adalah penghasil minyak kelapa sawit kedua terbesar di dunia setelah Malaysia. Untuk meningkatkan produksi kelapa sawit dilakukan kegiatan perluasan areal pertanaman, rehabilitasi kebun yang sudah ada dan intensifikasi khusus untuk perkebunan sawit rakyat. Permasalahan umum yang dihadapi antara lain rendahnya produktivitas dan mutu produksinya. Produktivitas kebun sawit rakyat rata-rata 16 ton ha $^{-1}$ tandan buah segar (TBS), sementara potensi produksi bila menggunakan bibit unggul sawit bisa mencapai 30 ton TBS per ha. Produktivitas CPO (Crude Palm Oil) perkebunan rakyat hanya mencapai rata-rata 2.5 ton CPO per ha dan 0.33 ton ha ${ }^{-1}$ minyak inti sawit (PKO), sementara di perkebunan negara rata -rata menghasilkan 4.82 ton $\mathrm{ha}^{-1} \mathrm{CPO}$ dan 0.91 ton $\mathrm{ha}^{-1} \mathrm{PKO}$, dan perkebunan swasta ratarata menghasilkan 3.48 ton $\mathrm{ha}^{-1} \mathrm{CPO}$ dan 0.57 ton $\mathrm{ha}^{-1}$ PKO. Tujuan dari penanaman kelapa sawit yaitu menghasilkan produksi yang optimal. Produksi optimal didapatkan dengan memahami faktor-faktor dan karakteristik yang mempengaruhi produksi dan diusahakan berada pada level yang optimum (Pahan, 2008).

Kelapa sawit mempunyai produktivitas lebih tinggi dibandingkan tanaman penghasil minyak nabati lainnya (seperti kacang kedelai, kacang tanah dan lain-lain), sehingga biaya produksi menjadi lebih rendah. Masa produksi kelapa sawit yang cukup panjang (22 tahun) juga turut mempengaruhi ringannya biaya produksi yang dikeluarkan oleh pengusaha kelapa sawit. Kelapa sawit juga merupakan tanaman yang paling tahan hama dan penyakit dibandingkan tanaman penghasil minyak nabati lainnya. Konsumsi per kapita minyak nabati dunia mencapai $25 \mathrm{~kg} /$ tahun setiap orangnya. Kebutuhan ini akan terus meningkat sejalan dengan pertumbuhan penduduk dan meningkatnya konsumsi per kapita.

Teknik budidaya yang diterapkan di kebun terdiri atas kegiatan pembukaan lahan hingga penanganan pasca panen. Salah satu teknik budidaya utama dalam pengusahaan kelapa sawit adalah pemanenan. Panen adalah serangkaian kegiatan mulai dari memotong tandan matang panen sesuai kriteria matang panen, mengumpulkan dan mengutip brondolan serta menyusun tandan di tempat pengumpulan hasil (THP) berikut brondolannya (SPO 2007). Menurut Lubis (1992), pengolahan tanaman yang sudah baku dan potensi produksi di pohon yang tinggi tidak ada artinya jika panen tidak dilaksanakan secara optimal. Oleh karena itu apabila ada buah matang yang tidak terpanen, mutu buah yang tidak sesuai dengan kriteria matang panen, dan buah yang dipanen tidak dapat segera dikirim ke pabrik agar segera dicari solusinya.

Kegiatan pemanenan memiliki tujuan untuk mendapatkan hasil panen dengan mutu yang baik. Tindakan yang dilakukan untuk mencapai tujuan pemanenan antara lain (a) pelaksanaan ketentuan panen seperti sistem panen, rotasi panen, kriteria matang panen dan persentase brondolan, (b) pelaksanaan angkutan panen segera mungkin ke pabrik dan (c) pelaksanaan pengolahan secepat mungkin (Astra Agro Niaga, 1996).

\section{BAHAN DAN METODE}

Penelitian ini dilaksanakan di Kabupaten Langkat Provinsi Sumatera Utara pada bulan Februari sampai Juni 2014. Pengumpulan data dan informasi yang diperlukan diperoleh berupa data primer dan sekunder. Data primer diperoleh melalui kerja dan pengamatan langsung ke lapangan seperti turut aktif dalam kegiatan di kebun, wawancara dan diskusi langsung dengan mandor, asisten dan karyawan kebun. Fokus utama pengumpulan data primer dan informasi adalah rotasi panen, angka kerapatan panen, tenaga panen, taksasi panen, produktivitas panen, dan mutu buah panen. Data primer yang diperoleh diantaranya adalah : a) Rotasi panen, b) Angka kerapatan panen, c) Tenaga panen, dan d) Produktivitas panen.

Pengamatan dilakukan pada tiga blok, setiap blok mengamati tiga puluh tanaman contoh dengan total pengamatan sebanyak 90 tanaman. Data sekunder diperoleh secara tidak langsung melalui arsip atau laporan perusahaan yang terdiri atas: a) Lokasi dan letak geografis, b) Keadaan tanah dan iklim, c) Luas areal dan tata guna lahan serta kondisi pertanaman, d) Data realisasi produksi TBS, e) Kandungan asam lemak bebas, f) Norma/aturan kerja, dan g) Struktur organisasi dan manejemen perusahaan.

Data primer dan data sekunder yang diperoleh dari hasil pengamatan dianalisis secara deskriptif dan kuantitatif. Analisis deskriptif digunakan dengan mencari nilai rata-rata dan 
persentase terlebih dahulu yang hasilnya akan dideskripsikan dengan pembanding norma baku dan standar yang berlaku di perusahaan. Analisis kuantitatif dilakukan menggunakan analisis statistik sederhana yaitu uji korelasi dan minitab 16.

\section{HASIL DAN PEMBAHASAN}

\section{Rotasi Panen}

Rotasi panen adalah selang waktu antara panen yang satu dengan panen berikutnya pada satu hanca panen. Rotasi panen yang ideal adalah 7 hari (PPKS, 2003). Kegiatan pemanenan memerlukan rotasi panen untuk mengetahui berapa hari dalam satu minggu kegiatan panen harus dilakukan. Terdapat dua rotasi panen dalam kegiatan pemanenan yaitu $5 / 7$ dan $6 / 7$. Rotasi panen 5/7 artinya adalah kegiatan pemanenan dilakukan dalam jangka waktu 5 hari dalam seminggu sedangkan rotasi panen 6/7 artinya kegiatan pemanenan dilakukan 6 hari dalam seminggu. Rotasi panen 5/7 dilakukan pada semester I sedangkan rotasi panen 6/7 dilakukan pada semester II (Tabel 1). Hal ini disebabkan produksi pada semester I lebih rendah dibandingkan semester II sehingga kekurangan produksi dapat ditutupi oleh produksi pada semester II.

Rotasi panen bermanfaat menjaga mutu buah dan kualitas buah yang akan dipanen. Rotasi panen yang terlalu cepat akan mengakibatkan banyaknya buah yang tidak bisa dipanen atau penurunan potensi buah (buah trek). Rotasi panen yang terlalu lambat dapat mengakibatkan tingginya losses seperti buah lewat matang, buah busuk, dan banyaknya brondolan tidak terkutip. Sarimanah (2008) menyatakan rotasi panen yang panjang akan mengakibatkan banyaknya jumlah brondolan yang disebabkan banyaknya tandan matang dan lewat matang di pohon. Hal tersebut mengakibatkan peluang kehilangan hasil berupa tandan matang tertinggal di pohon dan brondolan tidak dikutip menjadi sangat tinggi sehingga menurunkan produksi dan produktivitas. Rotasi panen yang terlalu cepat (dibawah 7 hari) dapat mengakibatkan pemanen cenderung memanen buah mentah (under ripe) untuk memenuhi basis panen.

Tabel 1. Rotasi panen pada semester I dan II

\begin{tabular}{|c|c|c|c|c|c|}
\hline \multirow[b]{2}{*}{ Kapveld } & \multirow[b]{2}{*}{ Hari } & \multicolumn{2}{|c|}{ Semester I } & \multicolumn{2}{|c|}{ Semester II } \\
\hline & & $\begin{array}{c}\text { Rata-rata luas } \\
\text { Kapveld panen (ha) }\end{array}$ & Luas (ha) & $\begin{array}{c}\text { Rata-rata luas } \\
\text { Kapveld panen (ha) }\end{array}$ & Luas (ha) \\
\hline I & Senin & 56.85 & 59.20 & 48.39 & 49.38 \\
\hline II & Selasa & 59.23 & 56.90 & 48.39 & 46.55 \\
\hline III & Rabu & 57.12 & 59.20 & 48.39 & 49.38 \\
\hline IV & Kamis & 57.52 & 54.52 & 48.39 & 45.81 \\
\hline $\mathrm{V}$ & Jumat & 55.99 & 56.92 & 44.79 & 48.79 \\
\hline VI & Sabtu & & & 48.39 & 48.83 \\
\hline Jumlah & & 286.74 & 286.74 & 286.74 & 288.74 \\
\hline
\end{tabular}

\section{Manajemen Pemanenan Kelapa Sawit}

Manajemen mengkoordinasikan aktivitas-aktivitas kerja sehingga dapat selesai secara efektif dan efisien melalui orang lain. Proses manajemen terdiri atas merencanakan (planning), mengorganisasikan (organizing), memimpin (leading), dan mengawasi (controlling) (Robbins dan Coulter 2005). Pada proses kegiatan pemanenan kelapa sawit, perencanaan mencakup kegiatan AKP (angka kerapatan panen) yang terdiri atas estimasi produksi, jumlah pemanen dan jumlah armada yang dibutuhkan, dan rotasi panen. Pengorganisasian mencakup struktur organisasi afdeling, pembagian pemanen menjadi dua kemandoran dan pembagian hanca panen. Kepemimpinan mencakup pada pelaksanaan panen yakni memastikan adanya alat pelindung diri (APD), kelengkapan alat panen dan bertanggung jawab atas seluruh kegiatan teknis di afdeling. Pengawasan mencakup kualitas buah yang dipanen, tangkai tandan dipotong pendek dan dibuat huruf $\mathrm{V}$, brodolan dikutip, pelepah dipotong dan disusun, dan tidak ada buah yang tertinggal di hanca maupun TPH (Tempat Pengumpulan Hasil).

\section{Angka Kerapatan Panen}

Angka kerapatan panen (AKP) merupakan metode taksasi produksi untuk memperkirakan jumlah produksi, kebutuhan tenaga panen, dan kebutuhan transportasi angkut esok hari. AKP dihitung sehari sebelum kegiatan panen dilakukan. Pelaksanaan kegiatan AKP dilakukan oleh krani AKP. Kegiatan AKP dilakukan siang atau sore hari. Tahapan dalam kegiatan AKP dimulai dengan menetapkan blok sampel untuk setiap kapveld yang akan dipanen esok hari. 
Pengambilan sampel dilakukan pada satu blok sampel mewakili tiap tahun tanam. Jumlah sampel minimal 5\% dari jumlah pohon dalam satu blok sampel.

Berdasarkan hasil pengamatan pada Tabel 2, penentuan AKP di kebun belum terealisasikan dengan baik. Hal ini terlihat pada selisih antara estimasi dan realisasi produksi di atas 5\%. Setiawan (2012) menyatakan perbandingan hasil estimasi dengan realisasi lebih dari 5\% dapat disebabkan oleh perubahan pemetakan blok baru dengan menggabungkan tiga atau lebih blok lama menjadi satu hamparan blok baru yang mengakibatkan adanya perbedaan tahun tanam dalam satu blok.

Penggabungan blok tersebut menjadikan unit kebun melakukan pemutihan terhadap tahun tanam. Pengambilan tahun tanam pada satu hamparan berdasarkan persentase paling besar tahun tanam pada hamparan kelapa sawit. Pada teknis di lapangan, perbedaan dapat disebabkan sedikitnya sampel contoh yang diambil dan kapveld panen yang berbeda antara tahun tanam, dimana pada tanaman tahun tanam 2006 hanya memiliki kapveld panen selama dua hari sedangkan pada tanaman tahun tanam 2002 memiliki kapveld panen selama lima hari. Faktor lain yang dapat menyebabkan perbedaan estimasi dengan realisasi di atas 5\% adalah kegiatan AKP belum sesuai dengan instruksi kerja. Petugas AKP hanya memperkirakan berdasarkan hasil panen sebelumnya tanpa melakukan perhitungan jumlah tandan matang pada pokok sampel. Hasil uji-t AKP estimasi dengan realisasi antar tahun tanam menunjukan hasil yang tidak berbeda nyata. Artinya selisih umur tanaman enam tahun tidak mempengaruhi potensi dan realisasi produksi kelapa sawit. Hal ini disebabkan penggunaan bibit kelapa sawit dari varietas dan asal bibit yang sama yaitu varietas tenera dari Marihat.

Tabel 2. Angka kerapatan panen per tahun tanam

\begin{tabular}{|c|c|c|c|c|c|c|c|}
\hline \multirow{2}{*}{$\begin{array}{l}\text { Tahun } \\
\text { tanam }\end{array}$} & \multirow{2}{*}{ Blok } & \multicolumn{2}{|c|}{ Jumlah pokok } & \multirow{2}{*}{$\begin{array}{c}\text { Buah } \\
\text { Matang }\end{array}$} & \multirow{2}{*}{ AKP } & \multicolumn{2}{|c|}{ Jumlah produksi } \\
\hline & & Seluruh & Diamati & & & Estimasi & Realisasi \\
\hline 2000 & F3 & 1020 & 102 & 24 & $4.25: 1$ & 4080 & 4050 \\
\hline 2000 & $\mathrm{H} 2$ & 1119 & 111 & 30 & $3.7: 1$ & 5100 & 4900 \\
\hline 2000 & J5 & 1231 & 123 & 12 & $10.25: 1$ & 2040 & 2250 \\
\hline 2006 & G3 & 377 & 37 & 6 & $6.17: 1$ & 2070 & 800 \\
\hline 2006 & I3 & 491 & 94 & 11 & $8.55: 1$ & 1870 & 1868 \\
\hline Rata-rata & & 937.6 & 93.4 & 16.6 & $6.58: 1$ & $2822^{\mathrm{tn}}$ & $2774^{\mathrm{tn}}$ \\
\hline
\end{tabular}

Keterangan: $\mathrm{tn}=$ tidak berbeda nyata pada taraf 5\%

\section{Tenaga Panen}

Tenaga panen atau karyawan pemanen merupakan faktor terpenting dalam pemanenan kelapa sawit di perkebunan. Kekurangan jumlah pemanen dapat menyebabkan kegiatan panen terganggu karena jumlah tenaga tidak akan mencukupi luasan panen yang ditargetkan perusahaan, sedangkan kelebihan tenaga akan menurunkan efisiensi kerja. Penghitungan dan penetapan jumlah pemanen yang ideal dalam satu afdeling kebun dapat dilakukan dengan menghitung perbandingan antara luas areal afdeling dengan perkalian jumlah kapel (rotasi panen) dan norma panen perusahaan.
Kebutuhan pemanen Afdeling II

$$
\begin{aligned}
& =482.73 \text { ha }:\left(5 \text { kapel } x 4 \text { ha } \mathrm{HK}^{-1}\right) \\
& =24.13 \approx 25 \text { orang }
\end{aligned}
$$

Hasil penghitungan jumlah pemanen menunjukkan bahwa jumlah pemanen ideal yang harus dimiliki oleh Afdeling II Kebun Tanjung Jati dengan areal seluas 482.73 ha dan rotasi panen 5/7 adalah sebanyak 25 orang. Hasil penghitungan ini sudah mendekati jumlah pemanen yang dimiliki oleh Afdeling II, yaitu sebanyak 29 orang, dengan distribusi seperti yang terdapat pada tabel 3 .

Tabel 3. Luas areal dan jumlah pemanen di Afdeling II

\begin{tabular}{cccc}
\hline Mandoran & $\begin{array}{c}\text { Luas areal } \\
\text { (ha) }\end{array}$ & $\begin{array}{c}\text { Inventaris pokok } \\
\text { (tanaman) }\end{array}$ & $\begin{array}{c}\text { Jumlah pemanenan } \\
\text { (orang) }\end{array}$ \\
\hline S & 252.31 & 33072 & 15 \\
K & 230.42 & 29683 & 14 \\
Jumlah & 482.73 & 62755 & 29 \\
\hline
\end{tabular}

Berdasarkan Tabel 3 luas areal yang dimiliki mandoran $\mathrm{K}$ seharusnya mendapatkan setidaknya tambahan satu atau dua pemanen lagi untuk memaksimalkan hasil panen di arealnya. Permasalahan yang sering terjadi adalah kurangnya pemanen pada saat kondisi 
buah sedang melimpah, khususnya pada mandoran dengan jumlah pemanen yang paling sedikit. Hal ini menyebabkan hanca panen sering tidak tuntas dipanen sehingga harus dilakukan panen ulang pada hari berikutnya. Kegiatan panen ulang sering menyebabkan terganggunya rotasi panen, bahkan bisa bertambah dari $5 / 7$ menjadi $6 / 7$. Hal ini terjadi akibat pemanen yang harus kembali memanen di hanca sebelumnya terlebih dahulu sebelum memanen di hanca yang sesuai dengan perhitungan rotasi.

\section{Produktivitas Kelapa Sawit}

Produksi dapat diukur dengan produktivitas yang merupakan hasil pembagian dari produksi dibagi dengan luas lahan yang dipanen. Sunarko (2007) menyatakan potensi produksi tanaman kelapa sawit ditentukan oleh beberapa faktor seperti jenis atau varietas kelapa sawit, umur tanaman, pemeliharaan tanaman, keadaan iklim, serangan hama dan penyakit serta jenis tanah atau kelas kesesuaian lahan.

Produktivitas kelapa sawit berdasarkan Tabel 4 belum sesuai dengan standar Marihat PPKS. Hal ini dapat dikarenakan kondisi iklim dan tanah, belum maksimalnya kegiatan aspek teknis (pemupukan dan pengendalian gulma), pencurian TBS di hanca maupun TPH, kegiatan panen yang tidak sesuai intruksi kerjadan kurangnya pengawasan panen. Kondisi tanah di adalah typic hapluduits dan masuk ke dalam kesesuaian lahan S3. Menurut Koedadiri (2004) kondisi seperti ini memerlukan penanganan dan pengelolaan yang khusus untuk meningkatkan produktivitas seperti pemberian pupuk anorganik yang cukup tinggi dan berimbang dengan konservasi tanah dan air yang tepat dan berkesinambungan.

Tabel 4. Produktivitas kelapa sawit 3 tahun terakhir

\begin{tabular}{ccccccc}
\hline & \multicolumn{6}{c}{ Produktiitas } \\
\cline { 2 - 7 } Tahun tanam & \multicolumn{2}{c}{2011} & \multicolumn{2}{c}{2012} & 2013 \\
\cline { 2 - 7 } & \multirow{2}{*}{ Produktivitas } & $\begin{array}{c}\text { Standar } \\
\text { marihat }\end{array}$ & Produktivitas & $\begin{array}{c}\text { Standar } \\
\text { marihat }\end{array}$ & Produktivitas & $\begin{array}{c}\text { Standar } \\
\text { marihat }\end{array}$ \\
\hline 2005 & 13.75 & 30.0 & 21.2 & 29.5 & 16.31 & 30.0 \\
2006 & 7.57 & 29.0 & 18.0 & 30.0 & 12.33 & 31.0 \\
\hline
\end{tabular}

Produktivitas kelapa sawit di afdeling II terdapat perbedaan antar kapveld. Hasil uji-t (Tabel 5) produktivitas antar kapveld. Hasil berbeda nyata antar kapveld tampak pada kapveld I dengan kapveld II dan kapveld IV serta kapveld II dengan kapveld III, sedangkan untuk perbandingan produktivitas kapveld lainnya tidak nyata. Hal ini dikarenakan kapveld I dijadikan sumber produksi dibandingkan dengan kapveld yang lain. Dikarenakan kapveld I memiliki kondisi tanah yang lebih bagus dan subur, pertumbuhan pohon pada kapveld ini juga cukup baik dan jumlah pohon pada kapveld tersebut lebih banyak dari pada kapveld lainnya. Optimalisasi produksi yang

Tabel 5. Hasil uji t produktivitas antar kapveld

\begin{tabular}{|c|c|c|c|c|c|c|}
\hline \multirow{2}{*}{ Perbandingan kapveld } & \multicolumn{6}{|c|}{ Rata-rata $\left(\mathrm{kg} \mathrm{ha}^{-1}\right.$ hari $\left.^{-1}\right)$} \\
\hline & Kapveld I & Kapveld II & Kapveld III & Kapv & t-hit & $\operatorname{Pr}>|t|$ \\
\hline Kapveld I x Kapveld II & 476.0 & 334.8 & 425.0 & 370.7 & 5.00 & $0.000^{* * *}$ \\
\hline Kapveld I x Kapveld III & & & & & 1.70 & $0.112^{\text {th }}$ \\
\hline Kapveld I x Kapveld IV & & & & & 3.70 & $0.003 * *$ \\
\hline Kapveld II x Kapveld III & & & & & -3.46 & $0.004 * *$ \\
\hline Kapveld II x Kapveld IV & & & & & -1.47 & $0.165^{\mathrm{tn}}$ \\
\hline Kapveld III x Kapveld IV & & & & & 2.06 & $0.060^{\mathrm{tn}}$ \\
\hline
\end{tabular}

Keterangan : ** = berbeda nyata pada taraf uji $1 \%$, tn = tidak nyata. telah dilakukan oleh kebun sebagai upaya dalam mengatasi kendala tersebut adalah dilakukannya pemupukan sehingga dapat memicu kesuburan tanah dan pertumbuhan pohon, selain pada kapveld yang masih sedikit mengimbangi dengan kapveld I.

Berdasarkan hasil penelitian dapat terlihat bahwa semakin tinggi nilai angka kerapatan panen maka produktivitas kelapa sawit semakin besar. Hal ini juga berbanding lurus dengan rotasi panen yang semakin panjang. Rotasi panen semakin panjang dikarenakan pada blok tersebut kegiatan panen bisa terjadi beberapa kali dalam blok. itu dilakukan juga penyisipan agar jumlah pohon 


\section{KESIMPULAN}

Aspek utama pemanenan kelapa sawit terletak pada rotasi panen, penentuan nilai AKP, tenaga kerja, dan upaya dalam mempertahankan produktivitas. Rotasi panen di Afdeling II dibagi menjadi dua, yaitu semester I dan II yang dijadwalkan sesuai dengan tinggi rendahnya produksi.Penentuan nilai AKP merupakan faktor utama dalam kegiatan panen karena menentukan estimasi produksi, jumlah tenaga kerja dan jumlah armada yang dibutuhkan. Penentuan nilai AKP yang sebagian besar kurang akurat menyebabkan tidak sesuainya jumlah produksi. Produksi dan produktivitas tanaman juga masih tergolong rendah jika dibandingkan dengan areal tanaman yang luas dikarenakan penentuan nilai AKP yang sebagian besar kurang akurat.

\section{DAFTAR PUSTAKA}

Adi, P. 2010. Kaya dengan Bertani Kelapa Sawit. Yogyakarta (ID): Pustaka Baru Pr.

Astra Agro Niaga. 1996. Pedoman Brevet Dasar II. Tanaman Kelapa Sawit. Jakarta (ID): Astra Agro Niaga. [Ditjenbun] Direktorat Jenderal Perkebunan.2011.Volume dan nilai ekspor, impor Indonesia [internet]. [diunduh pada 2013 Agustus 12]. Tersedia pada http://ditjebun.deptan. go.id.

Koedadiri, A.D. 2004. Produktivitas kelapa sawit generasi pertama pada tanah ultisol di beberapa wilayah perkebunan kelapa sawit Indonesia. Warta PPKS. 12 (2-3): 47-59.

Loebis, B., Tobing, P.L. 1989. Potensi Pemanfaatan Limbah Pabrik Kelapa Sawit. Bul. Perkebunan 20 (1): 49-56.

Lubis, A.U. 1992. Kelapa Sawit (Elaeis guenensis Jacq.) di Indonesia. Sumatera Utara (ID): Pusat Penelitian Kelapa Sawit.
Naibaho, P.M. 1990. Diversifikasi minyak sawit dan inti sawit dalam upaya peningkatan daya asing dengan minyak nabati lainnya. Bul. Perkebunan 21 (2): 107-124.

Pahan, I. 2008. Panduan Lengkap Kelapa Sawit. Jakarta (ID): Penebar Swadaya.

Pahan, I. 2012. Panduan Lengkap Kelapa Sawit Manajemen Agribisnis dari Hulu hingga Hilir. Jakarta (ID): Penebar Swadaya.

[PPKS] Pusat Penelitian Kelapa Sawit. 2003. Budidaya Kelapa Sawit. Medan (ID): Pusat Penelitian Kelapa Sawit.

Robbins, S.P., Coulter, M. 2005. Manajemen Edisi ke-8. Slamet $\mathrm{H}$, penerjemah; Indriani, editor. PT Indeks, Jakarta. Terjemahan dari: Management.

Sarimanah. 2008. Manajemen Panen di Perkebunan Kelapa Sawit (Elaeis guineensis Jacq.)Mustika Estate, PT Sajang Heulang, Minamas, Kalimantan Selatan. [Skripsi]. Institut Pertanian Bogor, Bogor.

Satyawibawa, I., Widyastuti, Y.E. 1999. Kelapa Sawit: Usaha Budidaya, Pemanfaatan Hasil, dan Aspek Pemasaran. Jakarta (ID): Penebar Swadaya.

Setiawan, K. 2012. Manajemen Panen Kelapa Sawit (Elaeis guineensis Jacq.) pada Lahan Gambut di kebun Mandah, PT. Bhumireksa Nusa Sejati, Minamas Plantation. [Skripsi]. Institut Pertanian Bogor, Bogor.

Sunarko. 2007. Petunjuk Praktis Budi Daya dan Pengolahan Kelapa Sawit. Jakarta (ID): Agromedia Pustaka.

Sunarko. 2009. Budidaya dan Pengelolaan Kebun Kelapa Sawit dengan Sistem Kemitraan. Jakarta (ID): Agromedia Pustaka. 